\title{
Identification of Neocosmospora ipomoeae causing tomato stem rot in Korea
}

\author{
Jin-Hyeuk Kwon ${ }^{1}$ - Okhee Choi $^{2}$ • Byeongsam Kang ${ }^{3} \cdot$ Yeyeong Lee $^{3} \cdot$ Jiyeong Park $^{3}$. \\ Dong-Wan Kang ${ }^{1}$ • Inyoung Han ${ }^{1}$ • Eun-Jee Park ${ }^{1}$ • Jinwoo Kim ${ }^{2,3}$
}

Received: 19 January 2017 / Accepted: 11 July 2017 / Published online: 26 July 2017

(C) Australasian Plant Pathology Society Inc. 2017

\begin{abstract}
Severe stem rot in hydroponically grown tomatoes was observed in Jinju, South Korea in early spring, 2016. Initial symptoms were water-soaked lesions on the lower stems, near the collar. Infected tomato plants gradually wilted leading to death of the plants. Advanced lesions were brown in color. Fungal isolates were identified by morphology and sequences of the gene encoding translation elongation factor 1-alpha (TEF1- $\alpha$ ). To fulfill Koch's criteria, pathogenicity tests were completed on potted 2-month-old tomato plants. The causal fungus was identified as Neocosmospora ipomoeae. This is the first report of tomato stem rot caused by Neo. ipomoeae in Korea.
\end{abstract}

Keywords Solanum lycopersicum L. · Translation elongation factor 1-alpha $\cdot$ TEF $1-\alpha$

In the early spring of 2016, severe stem rot in hydroponically grown tomatoes (Solanum lycopersicum) was observed in Jinju, South Korea. The initial symptoms were water-soaked lesions on the lower stems, near the collar. Infected tomato plants gradually wilted leading to death of the plants. Severe lesions were brown in color (Fig. 1a). Abundant orange and

Jin-Hyeuk Kwon and Okhee Choi contributed equally to this work.

Jinwoo Kim

jinwoo@gnu.ac.kr

1 Gyeongsangnam-do Agricultural Research and Extension Services, Jinju 52733, Republic of Korea

2 Institute of Agriculture \& Life Science, Gyeongsang National University, Jinju 52828, Republic of Korea

3 Division of Applied Life Science, Gyeongsang National University, Jinju, Republic of Korea red colored-perithecia were evident in infected lesions. Jee et al. (2005) reported paprika stem and fruit rot caused by Neocosmospora haematococca, but tomato stem rot has never been reported in Korea (Korean Society of Plant Pathology 2009; Farr and Rossman 2014). We thus sought to isolate and identify the fungus associated with recent occurrences of stem rot. One isolate was shown to be pathogenic on healthy tomato plants.

We sampled tomato plants with stem rot symptoms. Fungi were isolated as previously described (Kwon et al. 2013), with a few modifications described as follows. Tissue samples (3$5 \mathrm{~mm}$ ) of both symptomatic and healthy stem tissue were surface-disinfected via immersion in $1 \%(w / v)$ sodium hypochlorite for $30 \mathrm{~s}$, and then washed three times in sterile distilled water; dried on sterilized filter paper; transferred to water agar; and incubated at $25^{\circ} \mathrm{C}$. Hyphal tips were transferred to potato dextrose agar (PDA). Five fungal isolates were isolated from each plant sample. A representative fungal isolate (KACC 48133) was deposited in the Korean Agricultural Culture Collection, National Academy of Agricultural Science, Jeonju, South Korea). Images were taken by light microscopy (Axioplan 2, Carl Zeiss, Jena, Germany) and scanning electron microscopy (LEO 1420VP, LEO Electron Microscopy Ltd., Cambridge, UK).

The fungus developed sexual perithecia on both infected plant tissues and agar media (Fig. 1a-h). The perithecia were pale orange to scarlet in color, and $120-180 \mu \mathrm{m}$ in diameter (Fig. 1b-c). Asci contained eight spores, were cylindrical to clavate. The ascospores were ellipsoid in shape, had a single septum, and measured 10-18 × 3-7 $\mu \mathrm{m}$ (Fig. 1d-f). Fungal colonies on PDA were pale brown in color (Fig. 1g). Microconidia were abundant, ellipsoidal to cylindrical in shape, contained one or two cells, and measured 8-17 $\times 2$ $4 \mu \mathrm{m}$. Macroconidia were abundant, cylindrical to falcate in shape, and measured 40-70 × 5-7 $\mu \mathrm{m}$ (Fig. 1i). 
Fig. 1 Neocosmospora ipomoeae on tomato. a, tomato stem rot; $\mathbf{b}$, enlarged perithecia on basal tomato stems; c, crushed perithecia; d, asci bearing ascospores; e, ascospores; f, ascospores viewed by SEM; $\mathbf{g}$, fungal colonies; $\mathbf{h}$, abundant perithecia produced on PDA after $30 \mathrm{~d}$; i, asexual reproductive structures of the microconidia and macroconidia; $\mathbf{j}$, symptoms induced $20 \mathrm{~d}$ after artificial inoculation. Bars: b-d $=10 \mu \mathrm{m}$; $\mathrm{e}=40 \mu \mathrm{m} ; \mathrm{f}, i=20 \mu \mathrm{m}$
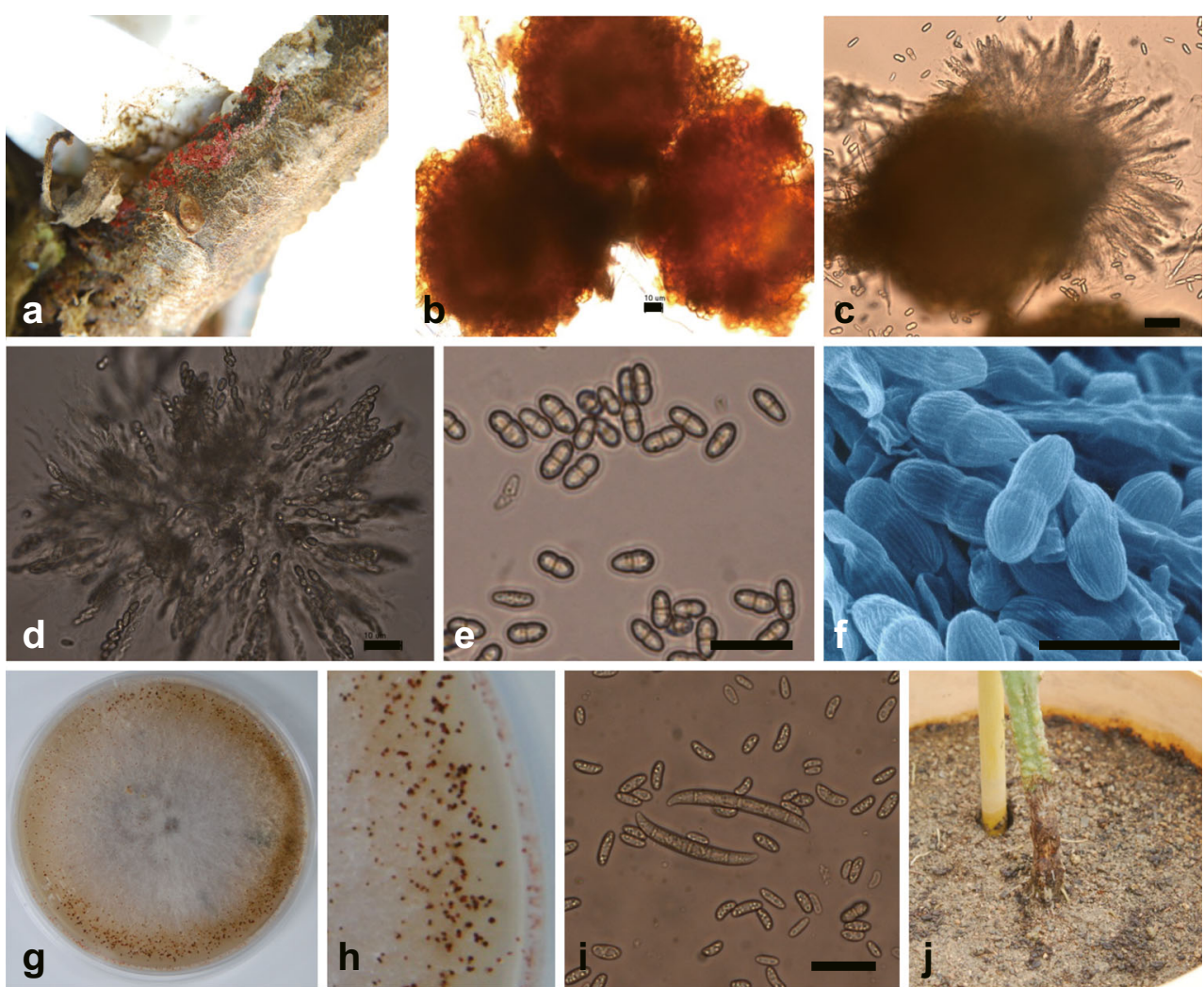

To identity the fungal isolate, part of the TEF1- $\alpha$ gene of KACC 48133 was amplified using the EF1 and EF2 primers (O'Donnell et al. 1998). Total DNA was extracted with the aid of an Exgene Plant-Fungal SV Mini Kit (GeneAll Biotechnology Co., Seoul, South Korea), in line with the manufacturer's instructions. PCR amplification was performed using a BIO-RAD T100 Thermal Cycler (Bio-Rad, Hercules, CA, USA) in PCR buffer (TaKaRa Bio Inc., Tokyo, Japan) containing each of the four dNTPs at concentrations of $200 \mu \mathrm{M}$. The primer concentrations were $1 \mathrm{mM}$; and each reaction mixture contained $1 \mu \mathrm{g}$ of target DNA and $1 \mathrm{U}$ rTaq DNA polymerase. Amplification proceeded over 30 cycles featuring template DNA denaturation at $98{ }^{\circ} \mathrm{C}$ for $30 \mathrm{~s}$, primer annealing at $60^{\circ} \mathrm{C}$ for $1 \mathrm{~min}$, and elongation at $70{ }^{\circ} \mathrm{C}$ for $1 \mathrm{~min}$. The amplification products were subjected to electrophoresis on $0.8 \%(w / v)$ agarose gels. PCR products were purified using a Gel Extraction Kit (Qiagen, Hilden, Germany) and cloned into the pGEM-T Easy Vector (Promega), according to the manufacturer's instructions. Sequencing proceeded using the M13F and M13R primers and a BigDye Terminator Cycle Sequencing Kit (Applied Biosystems, Foster City, CA, USA) following the manufacturer's instructions. The sequences were subjected to BLAST analysis. The BLAST search of the TEF1- $\alpha$ gene sequence (653 bp, GenBank Acession no. MF344651) yielded a 100\% homology with the TEF1- $\alpha$ sequence of Neo. ipomoeae MAFF 237667 (AB513843) and 23A (KF483867) (Nakayama and Aoki 2010; Moine et al. 2014).
Phylogenetic analysis was performed using MEGA version 7 (MEGA, Tempe, AZ, USA; http://www.megasoftware. net/) employing the maximum parsimony method (Kumar et al. 2016). The sequence of Neo. plagianthi strain NRRL 22632 was chosen as the outgroup for phylogenetic comparisons. Phylogenetic analyses of TEF1- $\alpha$ gene sequences revealed that KACC 48133 lay within a clade of Neo. ipomoeae strains (Fig. 2). Our phylogenetic results were similar to those of other studies (Romberg and Davis 2007; Nakayama and Aoki 2010). Sherbakoff (1915) reported the striate rot of potato caused by Fusarium striatum in Colorado. It was considered as Nectria ipomoeae associated with a sexual state (Nirenberg and Brielmaier-Liebetanz 1996). Nectria ipomoeae has been synonymised as Neocomospora ipomoeae by Lombard et al. (2015).

Pathogenicity tests were performed as previously described, with a few modifications (Kwon et al. 2013). The pathogenicity of isolate KACC 48133 on potted 2-monthold greenhouse tomato plants was explored. The fungus was grown on PDA plates at $25^{\circ} \mathrm{C}$ for about $10 \mathrm{~d}$ prior to inoculation. Culture plates were flooded with sterile distilled water and rubbed with an artist's paintbrush (with bristles) to obtain conidial suspensions, which were then filtered through sterile cheesecloth and suspended to $3 \times 10^{4}$ conidia/ml in sterile distilled water. Thirty-microliter amounts of these suspensions were injected into tomato plant stems $2 \mathrm{~cm}$ above the collar, covered with sterilized cotton, and sealed with Parafilm. Sterile distilled water was next injected to moisten the cotton. 
Fig. 2 A phylogenetic tree based on analyses of TEF $1-\alpha$ gene sequences of Fusarium and Neocosmospora spp. using the maximum parsimony method. DNA sequences from the NCBI nucleotide database were aligned using ClustalW. Numbers above branches indicate bootstrap values. The isolate infecting tomato described in the present paper is bold

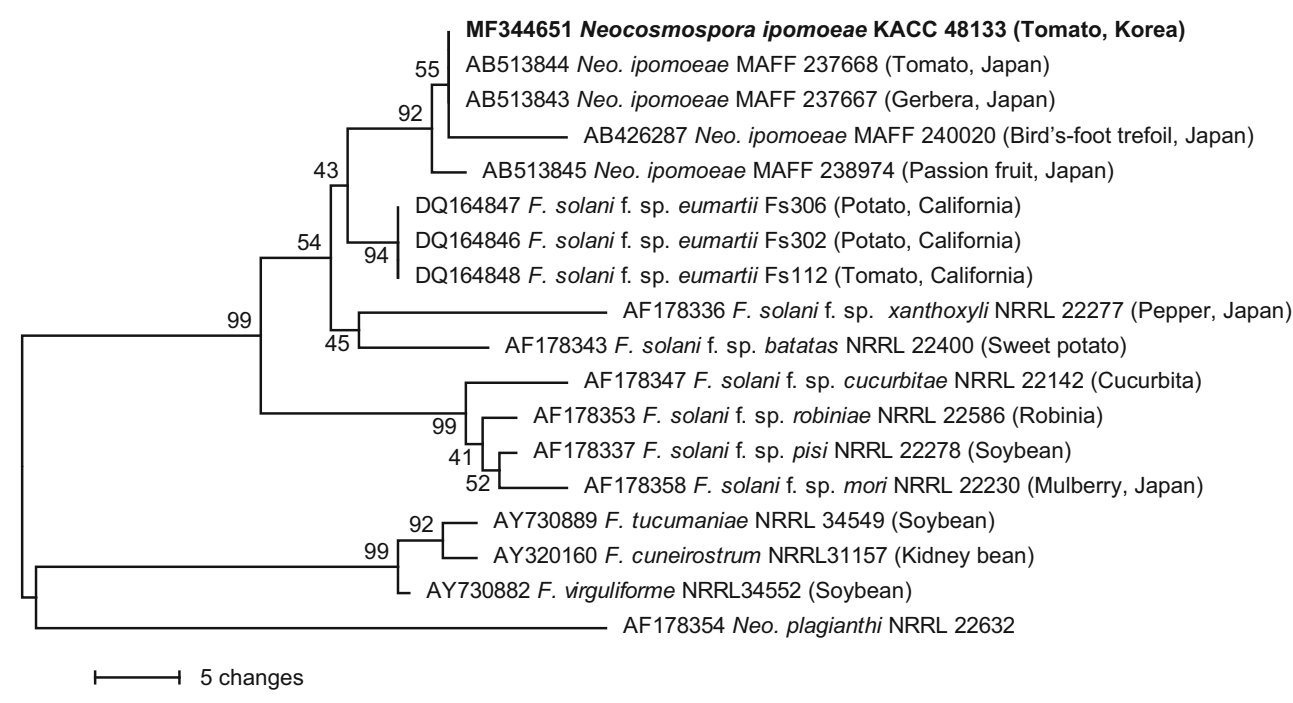

The controls were inoculated with sterile distilled water. All experiments were performed in triplicate. Plants were maintained in a greenhouse at room temperature (approx. $26{ }^{\circ} \mathrm{C}$ ) for $30 \mathrm{~d}$. Plants inoculated with conidial suspensions began to exhibit water-soaking symptoms $14 \mathrm{~d}$ after inoculation. At 20 d, all inoculated stems exhibited necrosis (Fig. 1j). Control stems were asymptomatic. Neocosmospora ipomoeae was re-isolated from lesions of inoculated plants. The morphological features of re-isolated fungi were the same as those of the original isolates, satisfying one of Koch's postulates.

We identified the fungus as Neo. ipomoeae based on the symptoms, morphological characteristics, molecular data, and pathogenicity data. To the best of our knowledge, this is the first report of tomato stem rot caused by Neo. ipomoeae in Korea. The recent occurrence of the disease indicates that stem rot may pose a serious threat to tomato production in Korea.

Acknowledgements This work was carried out with the support of Cooperative Research Program for Agriculture Science \& Technology Development (Project No. PJ01082304), Rural Development Administration, Republic of Korea.

\section{References}

Farr DF, Rossman AY (2014) Fungal databases, systematic mycology and microbiology laboratory, ARS, USDA Internet Resource: http://ntars-gringov//fungaldatabases/ Verified December 30, 2016
Jee HJ, Ryu KY, Shim CK, Nam KW (2005) Occurrence of stem and fruit rot of paprika caused by Nectria haematococca in Korea. Plant Pathol J 21:317-321

Korean Society of Plant pathology (2009) List of plant diseases in Korea, 5 th ed. $853 \mathrm{pp}$

Kumar S, Stecher G, Tamura K (2016) MEGA7: molecular evolutionary genetics Aanalysis version 7.0 for bigger datasets. Mol Biol Evol 33:1870-1874

Kwon JH, Choi O, Kim J (2013) Fusarium oxysporum causing wilt and stem rot in Chrysanthemum $\times$ morifolium in Korea. Plant Dis 97 : 1118

Lombard L, van der Merwe NA, Groenewald JZ, Crous PW (2015) Generic concepts in Nectriaceae. Stud Mycol 80:189-245

Moine LM, Labbé C, Louis-Seize G, Seifert KA, Bélanger RR (2014) Identification and detection of Fusarium striatum as a new record of pathogen to greenhouse tomato in northeastern America. Plant Dis 98:292-298

Nakayama K, Aoki T (2010) Foot rot of tomato, a new disease in Japan, caused by Fusarium solani f. sp. eumartii. Jpn J Phytopathol 76:7-16

Nirenberg HI, Brielmaier-Liebetanz U (1996) Nectria ipomoeae Halst., anamorph: Fusarium striatum Sherb. an Passiflora edulis Sims. Nachrichtenbl Dtsch Pflanzenschutzdienst 48:270-275

O’Donnell K, Kistler HC, Cigelnik E, Ploetz RC (1998) Multiple evolutionary origins of the fungus causing Panama disease of banana: concordant evidence from nuclear and mitochondrial gene genealogies. Proc Natl Acad Sci U S A 95:2044-2049

Romberg MK, Davis RM (2007) Host range and phylogeny of Fusarium solani f. sp. eumartii from potato and tomato in California. Plant Dis 91:585-592

Sherbakoff CD (1915) Fusaria of potatoes. Mem Cornell Univ Agric Exp Stn 6:87-270 